\title{
The Study on Heat Transfer of the Bathtub
}

\author{
Ziman Guo ${ }^{1, a}$ \\ ${ }^{1}$ North China Electric Power University, Baoding 071000, China; \\ aguo2014024@163.com
}

\begin{abstract}
In the paper, we develop a model of temperature of tub water with energy conservation law. We consider the water in the bathtub at a standstill, continuous injection to the bathtub and an equation of inflow and discharge. Energy conservation law and thermal balance equation are utilized to analysis heat exchange (people and water, surface water and air, outside surface of bathtub wall and air). Moreover, we calculate heat changes due to heat convection, conduction and radiation. The changing of water temperature is approximately linear to the time in a short period.
\end{abstract}

Keywords: Energy Conservation, Heat Exchange, Water Temperature.

\section{Introduction}

The bathtub is a common bathroom equipment. After a day's fast-paced work, people go back home feeling worn out. Laying immersed in a hot bathtub is a good idea to relax themselves. It can help them wash out tiredness, perspiration, dust and restlessness. The bathtub can bolster happiness greatly.

Early bathtubs in England tended to be made of cast iron, or even tin and copper with a face of paint applied that tended to peel with time. In the U.S., the commoditized bathtub first appeared is in the $1840 \mathrm{~s}^{[1]}$. At the beginning of 20th century, American manufacturers started to produce porcelain bathtub. Comparing to the cast-iron bath, ceramic bathtub is much easier to clean up and have a greater possibility of a wide range of shape. Moreover, it is better to display modernity, simple texture. The bathtub accommodated the most basic of human functions, but Americans used modern technology, plumping, fixtures, and bathroom spaces as identifications of their social status ${ }^{[2]}$.

The quantity of bathtub in America is pretty large. Also, the water and energy consumption from bathtubs is large. So we aim to study the heat transfer of the bathtub and calculate the temperature variation over time of the bathtub.

\section{Model hypothesis}

(1) About the heat exchange between the person and water in the bathtub, we only consider the effect of convection.

(2) Indoor air flows slowly, so we think thermal conduction is the main method of heat exchange between the bathtub and outside air.

(3) We consider the convection between outside air and water in the bathtub as the primary way of heat transfer.

(4) We neglect kinetic energy back into heat energy when water from the infall into bathtub.

(5) We do not think about water evaporate.

\section{Model preparation}

Size of the bathtub: The average height of male is $176.022 \mathrm{~cm}$, and weight is $88.677 \mathrm{~kg}^{[3]}$. On the basis of it, we design a simple bathtub as follows. The plan is as Figure1 


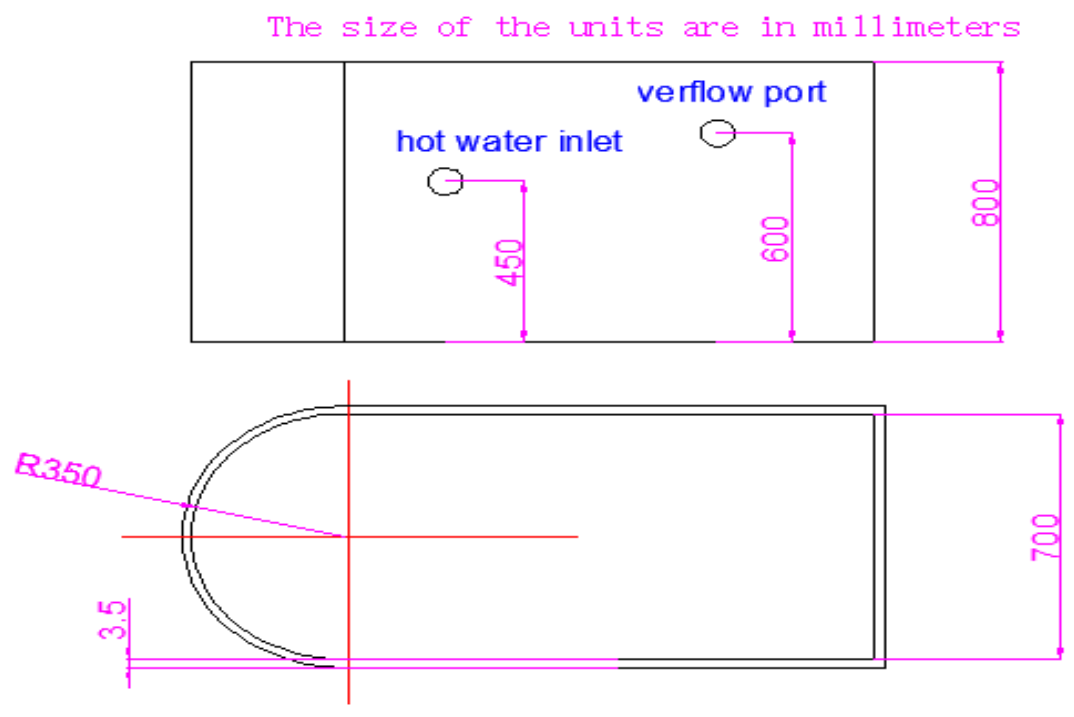

Figure 1. Plan of the tub

Parameters: In the section, we use some symbols for constructing the model as follows:

Table 1. Model Parameters

\begin{tabular}{ll}
\hline Parameters & Meaning \\
\hline$C$ & Specific heat of water \\
$m_{0}$ & Mass of the water when people get into the tub \\
$T$ & Real-time temperature of the water in the bathtub \\
$T_{1}$ & Temperature of the hot water from the hot faucet \\
$T_{2}$ & Indoor air temperature \\
$T_{3}$ & Temperature of the out surface of the tub wall \\
$T_{r}$ & Temperature of the people \\
$S_{0}$ & Area of the bottom of the tub \\
$S_{1}$ & Contact area between water and the surface of the tub wall \\
$S_{2}$ & Contact area between water and air \\
$S_{r}$ & Superficial area of the people \\
$\lambda$ & Thermal conductivity of acrylic \\
$d$ & Thickness of the tub wall \\
$H_{1}$ & Coefficient of heat transfer of the tub wall \\
$H_{2}$ & Coefficient of heat transfer of water \\
$V_{r}$ & Volume of the person \\
\hline
\end{tabular}

Other symbols instructions will be given in the text.

\section{Heat transfer of the bathtub}

When the person get into the tub, the temperature and height of the water in the bathtub is comfortable. $m_{0}$ is the mass of water at this stage. Later, none of water is injected into bathtub and the water content is certain. We consider a period $(t, t+d t)$ and the temperature is $(T, T+d T)$. 


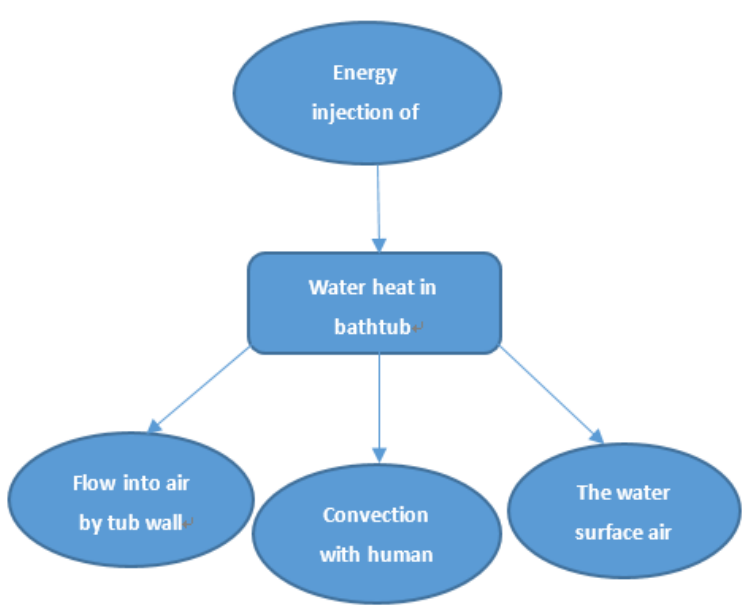

Figure 2. Heat Exchange

$Q_{1}$ Variation of heat energy of the water in the bathtub:

$$
Q_{1}=C m_{0}(T+d T-T)=C m_{0} d T
$$

$Q_{2}$ Energy loss due to the heat exchange between the tub wall and air:

Energy loss of convection is

$$
H_{1} S_{1}\left(T_{3}-T_{2}\right) d t
$$

Energy loss of heat conduction is

$$
\frac{S_{1} \lambda\left(T-T_{2}\right)}{d} d t
$$

Energy loss of heat radiation is

$$
\varepsilon \sigma_{1} S_{1}\left(T_{3}^{4}-T_{3}^{3}\right) d t
$$

Thus, we have

$$
Q_{2}=\left(H_{1} S_{1}\left(T_{3}-T_{2}\right)+\frac{S_{1} \lambda\left(T-T_{2}\right)}{d}+\varepsilon \sigma_{1} S_{1}\left(T_{3}^{4}-T_{3}^{3}\right)\right) d t
$$

$Q_{3}$ Energy loss due to the heat exchange between the water surface and outside air:

Energy loss of convection is

$$
H_{2} S_{2}\left(T-T_{2}\right) d t
$$

Energy loss of heat conduction is $W$.

Energy loss of heat radiation is

$$
\varepsilon \sigma_{2} S_{2}\left(T_{3}^{4}-T_{3}^{3}\right) d t
$$

Thus, we have

$$
Q_{3}=\left(H_{2} S_{2}\left(T-T_{2}\right)+W+\varepsilon \sigma_{2} S_{2}\left(T_{3}^{4}-T_{3}^{3}\right)\right) d t
$$

$Q_{4}$ Energy loss due to the heat exchange between the person and the water in the tub:

Energy loss of convection is

Energy loss of heat conduction is

$$
H_{r} S_{r}\left(T-T_{r}\right) d t
$$

$$
\frac{S_{1} \lambda_{r}\left(T-T_{r}\right)}{d_{r}} d t
$$

Energy loss of heat radiation is

$$
\varepsilon_{r} \sigma_{r} S_{r}\left(T_{r}^{4}-T_{r}^{3}\right) d t
$$


We have

$$
Q_{4}=H_{r} S_{r}\left(T-T_{r}\right) d t+\frac{S_{1} \lambda_{r}\left(T-T_{r}\right)}{d_{r}} d t+\varepsilon_{r} \sigma_{r} S_{r}\left(T_{r}^{4}-T_{r}^{3}\right) d t
$$

$Q_{5}$ Total energy loss: Total energy loss is a sum of the heat exchange between tub wall and air, water surface and air, the person and water in the bathtub. We have:

$$
Q_{5}=Q_{2}+Q_{3}+Q_{4}
$$

$$
Q_{5}=\left(\begin{array}{l}
H_{1} S_{1}\left(T_{3}-T_{2}\right)+\frac{S_{1} \lambda\left(T-T_{2}\right)}{d}+\varepsilon \sigma_{1} S_{1}\left(T_{3}^{4}-T_{3}^{3}\right)+ \\
H_{r} S_{r}\left(T-T_{r}\right)+\frac{S_{1} \lambda_{r}\left(T-T_{r}\right)}{d_{r}}+\varepsilon_{r} \sigma_{r} S_{r}\left(T_{r}^{4}-T_{r}^{3}\right)+ \\
H_{2} S_{2}\left(T-T_{2}\right)+W+\varepsilon \sigma_{2} S_{2}\left(T_{3}^{4}-T_{3}^{3}\right)
\end{array}\right) d t
$$

For the surface of the bathtub wall, energy loss from convection and radiation is far less than conduction. Therefore, we can neglect them. In like manner, as to the surface water, energy loss from conduction and radiation is extremely small compared with convection. Also, we do not calculate them ${ }^{[4]}$. And then, we can get simplified result:

$$
Q_{5}=\left(\frac{S_{1} \lambda\left(T-T_{3}\right)}{d}-H_{2} S_{2}\left(T-T_{3}\right)-H_{r}\left(T-T_{r}\right) S_{r}\right) d t
$$

As we all know, the law of conservation of energy states that the total energy of an isolated system remains constant-it is said to be conserved over time. On the basis of it, we can get a balanced equation as follows:

$$
\begin{gathered}
Q_{1}=-Q_{5} \\
\left\{\begin{array}{l}
C m \frac{d T}{d t}=-\frac{S_{1} \lambda\left(T-T_{3}\right)}{d}-H_{2} S_{2}\left(T-T_{3}\right)-H_{r}\left(T-T_{r}\right) S_{r} \\
T(t=0)=T_{0}
\end{array}\right\}
\end{gathered}
$$

In the process, the heat energy variation of the water in the tub is the total decrement of the heat energy of the water.

\section{Results of the Model}

Importing relevant data, we can get the relationship between the temperature and time:

$$
T=15.754 / \exp (0.0005993 t)+298.38
$$

The time of temperature from upper limits to lower temperature is about $2265.4 \mathrm{~s}$, approximately37.75 minutes.

\section{References}

[1]. Wilkie, Jacquelines. "Submerged Sensuality: Technology and Perceptions of Bathing.” Journal of Social History, Vol, 19, No.4(1986)

[2]. Jennings J. Le Corbusier's “Naked”:“Absolute Honesty” and (Exhibitionist) Display in Bathroom Settings[J]. Interiors, 1917, 2(3): 307-332.

[3]. Information on: http://www.cdc.gov/nchs/fastats/body-measurements.htm

[4]. Daqian Li. Mathematical Contest in Modeling of Chinese College. Beijing: Higher Education Press, 2001. 